\title{
Total Quality Management in Saudi Higher Education
}

\author{
Khadijah Mohammed \\ Alzhrani \\ Information System \\ department \\ Faculty of Computing \& \\ Information Technology \\ King Abdulaziz University \\ Jeddah, Saudi Arabia
}

\author{
Bashayer Ali Alotibie \\ Information System \\ department \\ Faculty of Computing \& \\ Information Technology \\ King Abdulaziz University \\ Jeddah, Saudi Arabia
}

\author{
Azrilah Abdulaziz, PhD \\ Information System \\ Department \\ Faculty of Computing \& \\ Information Technology \\ King Abdulaziz University \\ Jeddah, Saudi Arabia
}

\begin{abstract}
TQM is considered as a philosophy of modern management that is newly entered into the education field after it has proved the effectiveness and success in other fields such as the industry. TQM has been adopted in most of Saudi universities, but only some of them show excellence in the adoption and implementation process. The aim of this paper is to highlight some Saudi universities that successfully adopting the TQM concept and gain a competitive advantage over their local as well as global competitors. This paper also proposed a model to establish better TQM practices, in order to efficiently adopt and implement TQM philosophy in higher education. The model was based on previous research and the findings gained from the experience of TQM in local universities with recommendations to guide the successful quality management implementation.
\end{abstract}

\section{Keywords}

Saudi Universities, Quality, Total Quality Management (TQM), Higher Education(HE), Continues Improvement, Academic accreditation.

\section{INTRODUCTION}

Total quality management (TQM) is considered as a philosophy of modern management, which depends on several modern concepts and philosophies based on a combination of basic administrative means, innovative efforts and specialized technical skills to improve the level of performance and keep continuous improvement.

The global transformations movement creates new conditions of economic, technical, political, social and cultural variables that make business organizations think twice about the quality of any objects that they will provide as products or services.

Since education is considered as a base of every single professional in the world. Therefore, recently Saudi universities have started to care more about quality management by implementing the total quality management concept. Quality in education means, in general, moving from the minimum required services to a culture of perfection and excellence, it aims excellence in education to produce independent people who can take part in society by encouraging creativity, innovation, and analysis thinking, which may help to build strong \& active society.

This paper focuses on the concept of adopting TQM in higher educational institutions to ensure continuous improvement and quality in higher education especially in Saudi Arabia, also presents an improved model of TQM implementation within higher education institutions that contains the most important elements of the educational process and provides suggestions to improve the overall quality management aspect.

\section{THE RESEARCH IMPORTANCE AND OBJECTIVE}

Recently, there has been an increased competition locally and globally in adopting and implementing TQM in higher education institutions. The purpose of the implementation in education area is to reach global university ranking and gain a competitive advantage. TQM conceder as one of modern quality management methods that have proved effectiveness in many educational institutions including most of the USA and the UK universities [1]. There is still a lack of research and studies about the interest of Saudi universities to adopt the TQM concept. Therefore, this study aimed the following objectives:

1) To explore the experiments, benefits and recommendation of TQM successful implementation in Saudi universities.

2) Identify best TQM practices to support the implementation of TQM concepts in the Saudi Arabia universities.

\section{THE RESEARCH PROPLEM}

Studies about TQM implementation in Saudi Arabia need to be increased, especially with the lack of involving all the important parts of the educational process, which may affect the performance and improvement of the educational institution for this purpose, a set of research question formulated as:

1) What is the TQM nature and concept in the institutions of higher education?

2) What is the influence of adopting TQM implementation in Saudi Arabia universities?

3) What are the best practices to help the TQM implementation in $\mathrm{HE}$ in order to improve the universities' qualities and the university rankings?

4) How to establish best TQM practices to support the implementation of total quality management?

\section{DEFINITION OF TOTAL QUALITY MANAGEMENT}

Quality has many definitions and concept; Some defined quality as excellence and superiority, others sees that quality is an assurance that there are less defects in services or products, while other assume that quality is about products features. Quality may also link to avoid losses accrued from failure. Therefore, Total Quality Management (TQM) concept 
can take many forms that contain different attributes, which are changing depend on organization goals.

TQM refers to the management method that, which will enhance the quality and productivity in organizations. It is an annual quality process, which moves towards the perfection of the vision of the organization. TQM means handling all the component of an organization, and components of all those who are affected with the quality of services.

The definition of Total Quality Management terms by concept is described below:

1) Total: all organization components are involved in defining and knowing what the customer needs and expectations through cooperative or individual efforts to achieve the organization goals.

2) Quality: achieving higher expectations and desires of customers and consumers.

3) Management: development of the organization administrative chart, and capable leaders who are capable of continuous improvement and maintain a high level of quality.

Therefore, TQM is considered as a management philosophy based on concepts of modern philosophies and basic management methods, innovative efforts and specialized technical skills in order to raise performance level and continuous improvement.

The International Organization for Standardization (ISO) defined TQM as a "management approach for an organization, centered on quality, based on the participation of all its members and aiming at long-term success through customer satisfaction, and benefits to all members of the organization and to society" [2].

The British Standard Institution (BSI) defines quality as "the totality of features and characteristics of a product or service that stands on its ability to satisfy the stated or implied needs" [3].

Quality has five different approaches [3], which are:

1) In terms of excellent and high standards.

2) In terms of consistency

3) As a fitness for purpose

4) As a value for money through efficiency and effectiveness

5) As transformative in terms of qualitative change.

The quality movement started with quality improvement project in manufacturing companies, subsequently it started to spread to other services organizations including banking, insurance, nonprofit institutions, healthcare, government and educational institutions.

Therefore, the main concept of TQM is changing from correcting problems after an incident to prevent it from happening from the beginning.

Quality requires a model for continuous improvement in designing, products and services, also for planning and changes implementation. This model called Quality Cycle or Deming Cycle, which also refers to Plan-Do-Check-Act (PDCA) Cycle. It's basically a four-step model for carrying out changes, and repeat over and over for constant improvement; it will be will discuss later in some details in the model phase.

\section{TOTAL QUALITY MANEGMENT IN HIGHER EDUCATION}

Establishing quality in education is an important funding since the major receiver is humans. Education quality is what shapes continuous wealth and wellness of societies. Education has an impact on evolution, intelligence, and expertise that will lead to an advancement in life. Almost all countries have a huge impact from the improvement of higher education, which is effectiveness in producing Reliable specialists to rule in the future. Quality improvement is a continuous process, and in order to enhance quality, educational institutions need to implement TQM strategy. Since the higher education has to be about quality and excellence higher education institutions should implement global quality management systems, which is in this case TQM.

TQM is utilized in academic settings, which provides guidance in educational institutions in order to continue improvement through the entire educational process. TQM intervention had to occur in the educational process with the involvement of all parts. Students, parents, teachers, leaders, systems, stakeholders, and relationships are considered as parts of the educational process [4]. In many cultures, the main issue in quality management is being effected by the higher education institutions old plans. While, people and growing environments mentioned as relations that increase the importance of quality [4]

The expanding of education worldwide, students studying in different countries are causing some concerns to educational institutions, especially HE sector. The use of new teaching and learning methods, changing forms of education delivery, and course content, are all in the concept of quality which has become an essential component of the educational process, continuous improvement and self-evaluation for its success [3].

In enhancing TQM in the educational process, HE institutions have to consider the key elements of TQM in order to improve the quality, which are leadership, continuous improvement, employee participation and empowerment and information management.

Leadership appears to be a major element in the TQM implementation; top managements should be committed and involve in creating and supporting a customer focus and high expectations, and defining goals. Information management able to assist the decision makers by providing the fast response and the best analysis through good managing of using data and information. Human resources examine staff recruitments and progress to compare it with the institution objectives while staff needs are being took cared by providing them with a healthy working environment to ensure their satisfaction and participations. As an extension Educational management inspect the process's aspects, including education design, learner-focused approach, education delivery, services and operations of the HE institution [5].

Therefore, involving all elements with awareness, commitment, motivation and continues measuring through implementation of TQM, the educational process will be effective and universities ranking and the quality of the graduates will enhance. Moreover, universities will create competitive HE environment. 
TQM has been known as a management policy that supported many institutions' progress towards their goals. TQM led to a culture based on trust, collaboration, teamwork, endless quality, enthusiasm for consistent progress, continuous learning and eventually a healthy environment to work at and lifelong learning. It also focuses on customer satisfaction, which is the student in this case, through a concept of "continuous improvement". TQM commit HE institutions to follow an outline to achieve quality [1].

TQM in HE has a huge effects, mainly on students where they are becoming in a healthy constant condition, willing to collaborate and determined, with the support of their society, environment is also becoming free from harm and maintains enough resources and abilities, contents and materials are showing in a significant syllabus, applying methods that are student-centered training techniques and enabling evaluation to promote education and lower differences, Guaranteeing intelligence outcome and capability that reach the national target for education.

TQM has become well adopted by educational leaders while universities are also adopting quality measures. Therefore, with the continuous and fast economical and educational development in the Kingdom of Saudi Arabia, has forced universities to implement modern management styles including TQM to achieve continuous improvement.

Highest ranking universities in Saudi Arabia are adopting TQM concept as the main methodology in ensuring quality, some of them even have specialized teams and head departments to manage TQM. King Abdul-Aziz University, for example, have a specific department for developing quality management, where they also share their achievements, visions, responsibilities, and plans through the university website [6].

\section{LITERATURE REVIEW}

\subsection{Review of a Few Studies about the Implementation of TQM in Some Saudi Universities}

Due to the lack of studies about the TQM implementation locally, there are studies about some Saudi universities that have differentiated adoption and implementation of TQM. Sohail and Sheikh (2004) addresses a business school known as The College of Industrial Management (CIM) which has implemented a quality system and has gained accreditation by The International Association to Advance Collegiate Schools of Business (AACSB). CIM is within King Fahad University of Petroleum and Minerals (KFUPM), which is a leading university in Saudi Arabia. Consequently, the paper discussed the processes and procedures carried out by CIM for developing the quality system to gain the accreditation at the behest of the college to be a leading provider in management education as well contribute to the development of the national economy. Also, Sohail and Sheikh conducted a study in order to systematically assess the service quality issues from the Saudi business student's perspective and to examine the additional effect of the accreditation by the AACSB by collecting information on the degree of the service quality performance offered by the college. Hence, Sohail and Sheikh hypothesize that "the accreditation should enhance the quality of service to the students". In order to measure the student's evaluation of service quality, a survey was conducted based on the list of critical factors that used to evaluate the quality of service offered by the college. The study concluded that "contact personnel" is the most influencing factor in the students' evaluation of service quality, the second factor is "physical evidence", Then followed by Reputation, Responsiveness, Access to Facilities and curriculum. Moreover, the students who are experiencing the service quality of the CIM before the accreditation felt that the service quality performance was better than expected through analyzing the views of students. The approach adopted by CIM may provide useful guidelines for many HEI in the Middle East region as well as across the globe [7].

According to Alsuhaimi (2012), a quantitative study was conducted to explore the implementation of TQM and its practices in the faculty of education in King Saud University and giving a picture of the present situation of the quality system. Consequently, Alsuhaimi formulate the study hypothesis as "long-term TQM adopters have significantly higher total productivity than short-term TQM adopters." The data was collected from 125 faculty members of the education faculty, through a structured questionnaire. Results were obtained by performing statistical tests including reliability test, analysis of modifications, correlation, and regression analysis [8]. The study showed that long-term TQM adopters have higher means in all TQM practices, which are Customer focus, leadership, design quality, strategic quality planning, people participation, Fact Based management and continuous improvement. Hence, this result provides general support for the relationships among the length of TQM implementation and quality management practices. TQM practices are correlated significantly with productivity, due to the correlation analysis, which presented that customer focus, design quality, and person participant has the stronger correlations with productivity. Alsuhaimi mentions the following recommendations: these TQM practices must be implemented in educational institutions in order to increase its faculty performance as well as institutional progress, Policy makers should look after the possibility of practices TQM, it may have an influence on the achievement of the faculty which in return increase the level of education and research within the university and in the country as a whole [8].

Aldaweesh and Alkaraghouli (2013) study aimed to investigate and discuss the level of awareness for the TQM concept and tools in the Saudi universities also provide a deeper understanding of TQM's developments in those universities. Data from this study will offer assistance to the Saudi universities in applying and utilizing the TQM concepts with the better leadership practice. In order to accomplish the study objectives an interpretive multiple case studies were used. Aldaweesh and Alkaraghouli in the first point concentrated on the importance of exploring the relevant review of TQM and Leadership practices and discussed the factors of both TQM and Leadership Styles in relation to HE. In addition, a conceptual Framework for improving Saudi universities was presented in order to provide the needs of higher education in the Saudi universities [5].

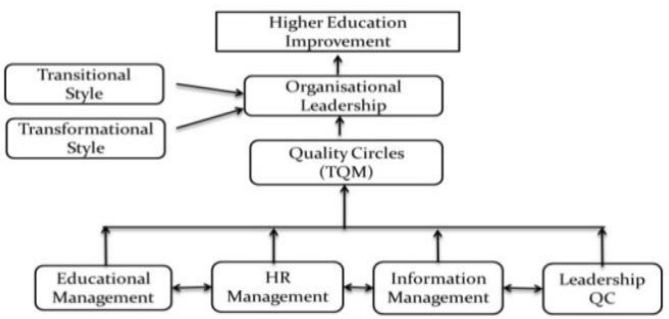

Fig 1: The conceptual framework of [5] 
According to Fig. 1, Quality Circles (QC) are an important technique to implement higher performance of TQM in higher education and should be directly involved with the four core elements of TQM which are leadership QC, Information management, Human resource management and Educational management. "Leadership is relevant to QC and the overall organization, and emerges as a major theme in the TQM implementation" [5]. Transactional style and Transformational style are the two styles to implement Leadership, where the leaders in the transactional style motivate their followers by exchanging rewards for performance as well as punishment while transformational leader focuses on the team-building, needs, values, motivation and collaboration of their followers and employees.

\subsection{Saudi Universities That Succeeded in Adopting the TQM Concept}

King Abdul-Aziz University took the initiative to adopt a quality theoretically and practically. So the quality was one of the basics of the strategic plan of the university, as the university has taken many developmental steps through the application of TQM to bring about a qualitative development to the duty cycle of the university, educational and administrative developments, and keep continues developments to achieve excellence in all processes in King Abdul Aziz University. Accordingly, the university was one of the first Saudi universities that have developed a comprehensive quality program to take over the application of quality in all sectors through the provision of advisory and executive education programs and to enable the University of competitiveness both locally and internationally. Moreover, King Abdul-Aziz University (KAU) establishes a department for TQM which focuses on planning, development and participation process in carrying out quality programs and it is concerned about monitoring quality, performance measurement and evaluation and putting standards and criteria for these processes aiming at continuing the developmental procedures [9].

The administration is committed to applying the principles of quality in terms of client focus, leadership, employee involvement, process management, system management, continuous development, and decisions construction of facts. In order to achieve management objectives and make it a reality, TQM department is committed to comprehensive training and continuous improvement to raise the efficiency of its employees and adopt their suggestions and ideas, provide the appropriate work environment, activating principle effective participation and contribution, self-monitoring and administrative follow-up to the Quality Management System by the coordinators of quality sectors of the university quality management department. Moreover, KAU website in the University Vice Presidency for the development contains many achievements of the TQM department resulting from the effective implementation of the TQM concept, and some of these achievements were the academic accreditation gained for some colleges at the university. For example, the Faculty of Computing and Information Technology and the College of Engineering Obtained the academic accreditation (ABET), which is an organization for the adoption of engineering and technical programs in many universities, where it verifies that the university is committed to sustaining and comprehensively in the field of education considering the quality of the education process. Subsequently, Faculty of Economics and Administration obtained the accreditation in 2010 by the American Accreditation Commission (AMBA). The Association of MBAs is the international impartial authority on postgraduate business education London-based. It is worth mention that Accreditation is at the heart of the Association of MBAs' commitment to developing standards in global postgraduate management education. Indeed, Students, Higher Education Institutions, Graduates, and Employers realize that AMBA accreditation is an assurance of quality [10].

On the other hand, The College of Industrial Management (CIM) which has a history of high-quality education for business and management within King Fahad University of Petroleum and Minerals (KFUPM) has gained AACSB accreditation which is a not-for-profit corporation of colleges, universities, business and professional organizations committed to excellence in management education. AACSB promotes continuous quality improvement of higher education for business administration and management. Consequently, the accreditation process focuses on the quality of educational activities through self-evaluation and peer review [7].

In addition, the Director of the Qassim University noted that the university established Agency for Development and Planning, Deanship of quality and accreditation and Deanship of University Development to ensure the purpose of supporting the Total quality concept within the faculties in the university. To improve the efficiency of the employees of the university and ensure the quality of their output to compete with outstanding scientific universities. The Vice President for the quality development and planning mention that the university planning agency launched the Rector Quality Award yearly to colleges, deanships and departments of the university in order to create positive competition in the quality application. As a result of adopting the concept of total quality and leadership commitment to TQM, Faculty of Science at the University of Qassim got the academic accreditation from the German Agency for international accreditation (ASIIN), which gave the college an academic quality by international certificate, although the university was newly established. Due to the overall management support and continuous effort of faculty members, administrators, students, and everyone is aware of the importance of quality and continuous improvement, commitment and cooperation on the effective application of TQM and interact with their outputs. Manager Quality Assurance Unit at Faculty of Science, Ahmad Hijazi pointed that the college started since its inception to participate in all academic accreditation. The development projects start from self-study project and then development of academic programs and finally a draft international accreditation programs the college [11].

Finally, Faculty of Engineering at King Saud University is seeking for academic accreditation (ABET). The main objective of accreditation is continuity in the process improvement of the education across all activities, The ABET Accreditation program consider the process of continuous improvement as essential element of the Academic Accreditation for the Engineering Education, which must meet a number of requirements which are called the education output and to support the continuous improvement of the engineering education process, Six Sigma was chosen as a way constructivism to improve operations effective standards and reduce mistakes rates by measuring and identifying opportunities for defects appearance and remove those flaws in a practical way. This will determine the levels of quality to the educational process outputs. Since the adopting of Six Sigma seeks to focus on the efforts to obtain educational services closer to maximum quality and workmanship degrees and the lowest cost in record time [12]. 
According to Antony Six Sigma was defined as " a wellestablished approach that seeks to identify and eliminate defects, mistakes or failures in business processes or systems by focusing on those process performance characteristics that are of critical importance to customers"[13]. Six Sigma quality management method is a program that aims to reduce or eliminate defective products and processes, whether processes in industrial or service [9]

It is worth mention that, the academic Accreditation is an effective tool to evaluate and enhance the educational process quality and continuity of development and is a proof of the efficiency of the scientific programs offered by the college or university. Access to Academic Accreditation enhances the confidence of the institution by the community and increases the chances of success and progress of the world and also contributes the college or the university to be more attractive. It provides a competitive research and teaching platform. In fact, the accreditation process is the result of the continuous effort of continuous improvement and development by both: Deans, agents, college and students, educational and administrative bodies, quality committees and development. However, it should consider the academic accreditation as a continuous process for development and continuous improvement. Due to that, the development process is a sustainable process requires continuous follow-up to the latest theories and developments in the educational and research curriculum.

\section{TQM IMPLEMENTATION FRAMEWORK}

\subsection{A Proposed Model to Implement TQM in $\mathrm{HE}$}

The proposed model development was based from literature review, which highlighted on the experiments of some Saudi universities to adopt and implement the TQM. Model elements consisting of the basic requirements of TQM, some effective practices in TQM implementation and PDCA Quality Cycle, as a tool to implement the TQM practices.

The PDCA (Plan-Do-Check-Act or Plan-Do-Check-Adjust) Cycle, also known as the Deming Cycle, was promoted by W. Edwards Deming, it is a continuous improvement model of processes, services, and products. Consist of four repetitive steps as shown in Fig. 2 [14]. It is a continuous cycle leads to improvement and place the organization closer to achieving its objectives. The Quality Cycle phase are:

1) Plan: set up objectives and processes to deliver substantial results in accordance to the targets or goals.

2) Do: execute the plan and Collect data for analysis in the following steps.

3) Check: analyze and study the results.

4) Act: take action where to standardize or improvements the process.

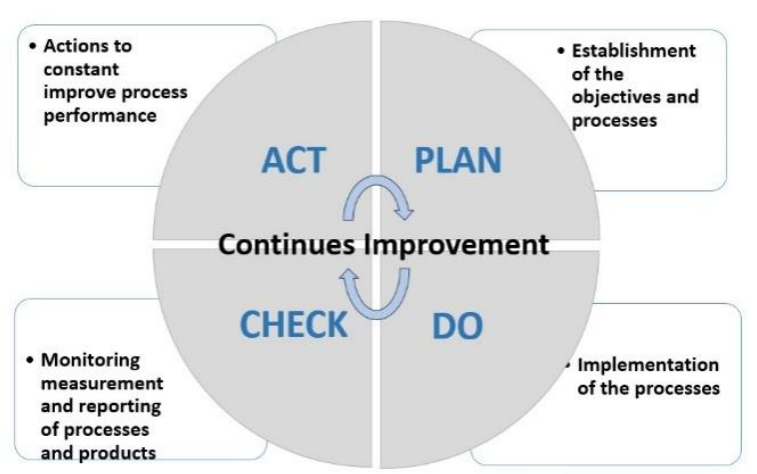

Fig 2: Improvement cycle stages [14]

Deming cycle is considered as a management method for the continuous quality improvement [15].

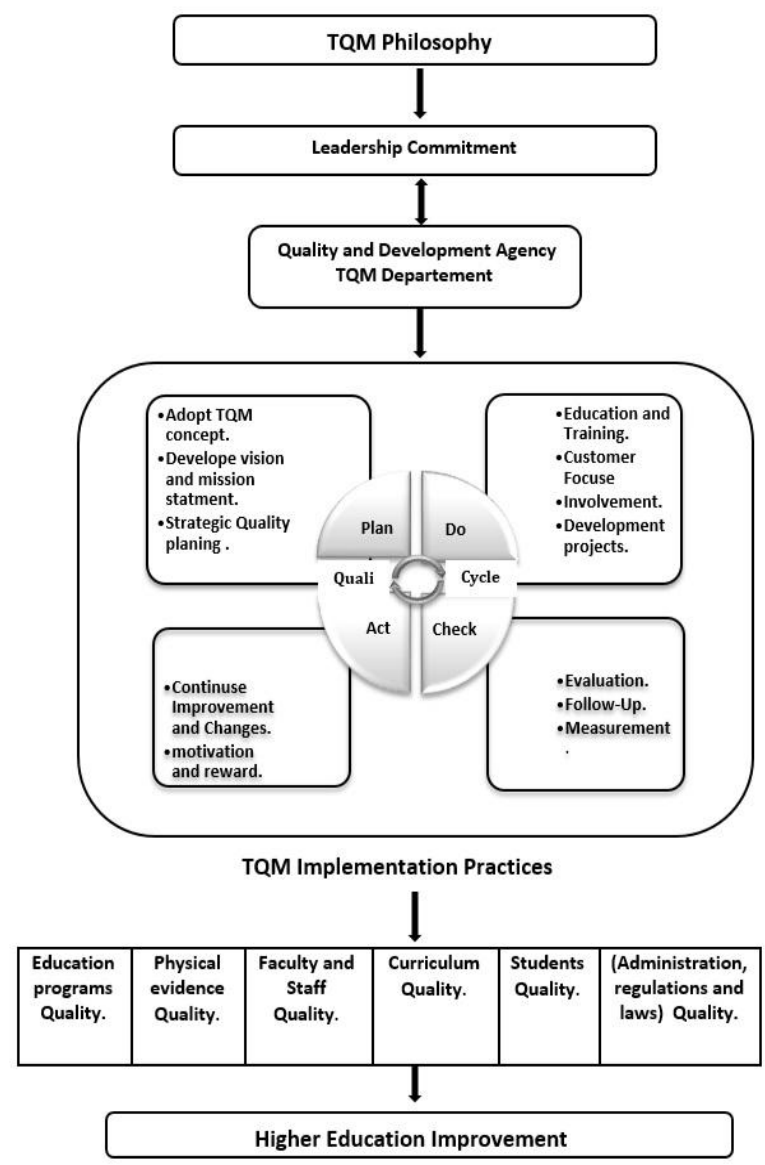

Fig 3: A proposed model for TQM implementation in HE

In Fig. 3, firstly TQM philosophy appears as an input to the higher education institution, secondly the adopting process requires leadership (Top management) commitment. Management assign at every level, but must take responsibilities in adopting the TQM philosophy, especially at the top. Indeed, reshape the enterprise culture does not succeed except through a support of the senior management to TQM concept as well as a support to the achievement of the desired objectives from the adoption of the concept.

Moreover, based on the leadership commitment for TQM, its importance to mention that "establishing the TQM culture 
among all employees in the institutions of higher education through publicizing an awareness and persuasion to boost confidence in TQM, lead in facilitating the acceptance of the implementation". For instance: the organization of conferences to introduce the concept and the importance of TQM to the institution.

Third, adoption of special department for a total quality management under the supervision of the top management as a form of empowerment, which means giving permission to the other employees to develop and utilize their skills and knowledge for the institution sake and participation process in carrying out the quality programs. Through identifying officials employees by selection of quality management team of managers, department's coordinator, and agents.

Fourth, The TQM implementation process by using (Deming cycle) as a tool or method to implement the TQM practices for continuous improvement by implementation through all four phases.

The four phases to implement the TQM practices in order to ensure constant improvement in the implementation are:

\subsubsection{Plan phase}

As what been mentioned above in the plane step, the administration mission is to set up Quality Policy in order to develop the objectives, processes, and procedures to deliver substantial results in accordance to the institutional goals.

When the commitment is made to implement TQM philosophy, a careful identification of the customers within the university setting needs to be achieved. The university customers include student, parents of the student and employers of the graduates, and the Board of Regents and the whole of society.

On the other hand, TQM department focuses on planning including forming a vision, mission, and objective statements of the quality management. The planning stage requires actions as listed below

- Establishing a quality assurance unit within most of departments, with the aim of internal audit and development.

- The help of consultants and specialized institutions in order to strengthen the foundation expertise and help in solving problems, especially in the early stages.

- Adopt internal quality measurements, cooperation with international accreditation organizations in order to develop a quality assurance system.

\subsubsection{Do phase}

This step adopts the processes and procedures that built in the planning phase in order to execute it. For instance, the education and training process. It's necessary for teaching and coaching workers about concepts and methods of TQM properly through a continuous and oriented education process for all categories and levels of the management, where the full awareness can be achieved through the effective training programs.

While TQM philosophy requires the involvement of all members of the institute, the educational process must be allinclusive especially the students so as enhancing their desired educational quality [16]. From this standpoint, it is worth mentioned some recommendations and suggestions:
- The need for teaching students the concept of TQM, either through training courses or teaching them theoretically in the Preparatory Year Program through insert it as a chapter of a (learning skills) course in order to strengthen responsibility for achieving the goals of the learning quality for each student and train them to exercise self-evaluation, Learning skills is a course that taught to each student in the preparatory program.

- Engage students in the quality process by establishing a quality club for students under the supervision of quality management in order to increase the students' awareness of the TQM concept and involve them in the management vision so as to encourage their cooperation and support to reach the desired goals.

\subsubsection{Check phase}

In the checking step, the process will be analyzed and the results will be studied. For example, a comprehensive evaluation, continuous follow-up of deviations from standards development and audit for continuity improves the operations.

\subsubsection{Act phase}

The analysis process will be followed by the acting step, where take an action to standardize or improvements the process.

Motivate the Participants is one of the important practices, continuity of the program depends entirely on enthusiasm involved in the process of improvement and development. Therefore, in order to promote for enthusiasm, any efforts made should be rewarded whether material or moral, seasonal or preferential. Treatment of deviations from the standards is another example of a process that should be done in this phase.

Finally, the outcome of the TQM implementation presented in the quality of higher education institution factors consisting of education program quality, physical evidence quality, faculty and staff quality, (administration, regulation, and lows) quality, students and curriculum quality. Raising the quality of the education program leads to quality education institution.

\subsection{Quality Enhancing By TQM and Other Methodologies}

In order to continue improvement, through the entire educational process, higher education institutions should implement global quality management methodologies and philosophies that work beside TQM to ensure progress and growth.

TQM, Six Sigma, and Lean Six Sigma have many, similar focus through continues process improvement, which are minimizing waste and resource, similar tools used for problem solving, process improvement, aid in data collection and interpretation, and provide the basis for decision making.

There will be a lot to gain if organizations are able to combine these three concepts, as they are complementary. Six sigma and lean are excellent roadmaps, which could be used by one or combined, together with the values in TQM. Since, they support the overall principles of TQM.

Several other methodologies also can be used beside TQM to enhance quality, not only in manufacturing field but can be applicable to all fields and institutions especially in higher education institutions. Awards are given as encouragement to 
these institutions such as EFQM Excellence Model for Higher Education Version 2003. ISO 9000, and the Baldrige Award.

\section{CONCLUSION}

Quality should be about constant improvement and excellence, and because of the higher education effect on the society and individuals, TQM should be adopted in a manner to raise quality in the educational process. Therefore, Saudi universities start to have their own quality and development department to keep track of the quality in the educational process by implementing the TQM.

TQM has many effects on the educational process and on the HE institution overall, those effects ensured continues improvement and progress towards excellent HE institution and hence competitive.

The TQM proposed model was presented based on the effective framework of quality in the educational institution based on previous studies.

TQM is about quality and competitive will kept increasing in the future, besides a well-organized TQM model methodology such as six sigma should be applied to ensure continues risen of the quality with more efficiency and more insurance.

\section{REFERENCES}

[1] [1] M.hasan and H.Al kassem. (2014). Total Quality Management in Higher Education: A Review. [Online] Available: $<$ http://www.macrothink.org/journal/index.php /ijhrs/article/view/6368/5214>. [Accessed 11 November 2015].

[2] Whatiskt. (2014) Total Quality Management. [Online] Available:<https://whatiskt.wikispaces.com/Total+Qualit y+Management>. [Accessed 11 November 2015].

[3] A.Khan. (2013). Total Quality Management in Higher Education Institution. [Online] Available: < http://indianresearchjournals.com/pdf/ijssir/2013/june/11. pdf >. [Accessed 11 November 2015].

[4] A.Zabadi. (2013). Implementing Total Quality Management (TQM) on the Higher Education Institutions - A Conceptual Model. [Online] Available: <http://www.todayscience.org/JFE/article/jfe.v1i1p42.pd f>. [Accessed 11 November 2015].

[5] M.Aldaweesh, W.Al-Karaghouli, and D.Gallear. (2013). The Effective Implementation of Total Quality Management and Leadership in Saudi Universities: A Review and Framework to Enhancing H.E. Strategy, [Online]Available:<http://bura.brunel.ac.uk/bitstream/24 38/8452/2/Fulltext.pdf>. [Accessed: 24 September 2015].
[6] KAU. (2015) Development and Quality management Department. [Online] Available: < http://totalquality.kau.edu.sa/Default.aspx?Site_ID=111\&Lng=AR $>$.[Accessed 11 November 2015].

[7] M.Sohail and N.Shaikh. (2004). Quest for excellence in business education: a study of student impressions of service quality. The international journal of Education Management. Vol. 18 pp. 58-65.

[8] ] M.Alsuhaimi. (2012). The Implementation of Total Quality Management in King Saud University. International Journal of Independent Research and Studies. Vol. 1 pp. 80-88.

[9] C.Sevnsson, M. Baesa and M.Bakhsh. (2013). Establishing a Lean Six Sigma Program in Higher Education.[Online]Available: $<$ http://repository.kaust.edu .sa/kaust/handle/10754/301467>. [Accessed 12 October 2015].

[10] KAU. (2014) Quality Management. [Online] Available: <http://totalquality.kau.edu.sa/Default.aspx?Site_ID=111 \&Lng=EN>. [ Accessed 28 October 2015].

[11] QU. (2015) news. [Online] Available: < http://www.cos.qu.edu.sa/news/Pages/ASIIN2.aspx > [Accessed 3 November 2015].

[12] A.Alahmary. Six Sigma in Higher Education, First International Conference on LSS for Higher Education. (sep 2013). [Online]. Available: <http://faculty.ksu.edu.sa/alahmari/Short\%20courses/Six \%20Sigma.pdf $>$ [Accessed 27 October 2015].

[13] J. Antony. (2014) Readiness factors for Lean Six Sigma journey in the higher education sector, International Journal of Productivity and Performance Management, Vol. 63 pp. 257-264.

[14] T.Waat, Micronarratives, Google Blogs, Virginia. (17 Agu 2010). The continual improvement cycle Available: http://micronarratives.blogspot.com/2010/08/continualimprovement-cycle-quality.html [Accessed 2 December 2015]

[15] IACBE. (2015) Continues Quality improvement and The Deming Cycle. [Online] Available: < http://iacbe.org/qacqi.asp >. [Accessed 28 November].

[16] R.Winn, and R.Green, (1998) Applying Total Quality Management to the Educational Process*, Int. J. Engng Ed. Vol.14, No.1, P.24-29. 